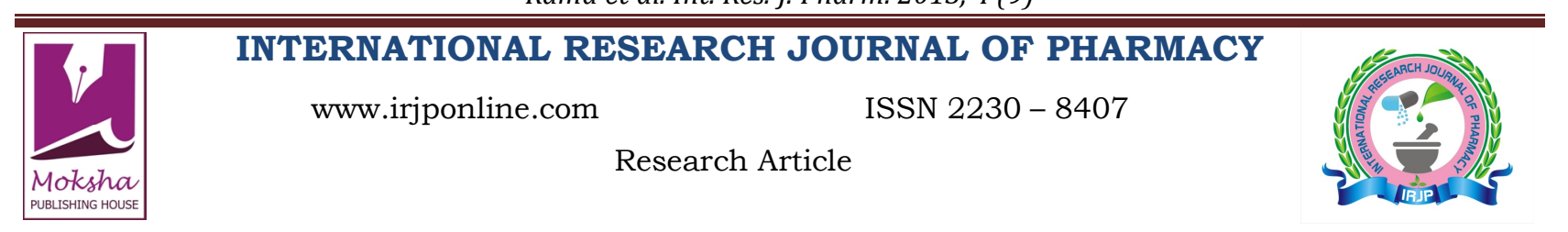

\title{
FORMULATION AND EVALUATION OF BILAYER TABLETS OF TWO INCOMPATIBLE DRUGS AMLODIPINE BESILATE AND LOSARTAN POTASSIUM
}

\author{
Rama*, Mitesh. R. Bhoot \\ Department of Pharmaceutics, C. L. Baid Metha College of Pharmacy, Thoraipakkam, Chennai, India \\ *Corresponding Author Email: ammujosu@yahoo.co.in
}

Article Received on: 19/08/13 Revised on: 07/09/13 Approved for publication: 10/09/13

DOI: $10.7897 / 2230-8407.04929$

IRJP is an official publication of Moksha Publishing House. Website: www.mokshaph.com

(C) All rights reserved.

\begin{abstract}
The main goal of this study was to develop a stable formulation for two incompatible anti hypertensive drugs Amlodipine besilate and Losartan potassium as an immediate release bi layer tablet and to evaluate its dissolution studies. The formulation development work was initiated with wet granulation for losartan potassium layer and direct compression for amlodipine besilate layer. Super disintegrants like Crospovidone, Sodium starch glycolate (SSG) were used in all the formulations and its role on disintegration and dissolution properties of the drug were studied. The prepared tablets were evaluated for weight variation, wetting time, hardness, thickness, friability, \% drug content, disintegration time, in vitro drug release. Formulation F8 showed a highest drug release of 84.02 $\%$ for amlodipine besilate and $90.08 \%$ for losartan potassium in 30 minutes which was selected as optimized formulation and considered for further studies. The stability studies, shown that the formulation $\mathrm{F} 8$ was stable enough at $40^{\circ} \mathrm{C} / 75 \% \mathrm{RH}$ for a period of 6 months. The results suggest the feasibility of developing bi layer tablets consisting of amlodipine besilate and losartan potassium for the convenience of patients with hypertension.
\end{abstract}

Keywords: Bi layer tablets, Amlodipine besilate, Losartan potassium, crospovidone, Sodium starch glycolate, in vitro drug release.

\section{INTRODUCTION}

Most conventional oral drug products, such as tablets and capsules, are formulated to release the active drug immediately after oral administration, to obtain rapid and complete systemic drug absorption. Bi layer tablets are prepared with one layer of drug for immediate release while second layer designed to release drug later, either as second dose or in an extended release manner. Bi layer tablet is suitable for sequential release of two drugs in combination, separate two incompatible substances, and also for sustained release tablet in which one layer is immediate release as initial dose and second layer is maintenance dose or both the layers can be immediate release. Hypertension is among the most common diseases of adults in industrialized countries and is one of the important modifiable risk factors for cardiovascular and renal disease. The goal of losartan potassium and amlodipine besilate (anti hypertensive drug) is to prevent complications of hypertension. Specially used for the treatment of patients with stage 1 and 2; essential hypertension in comparison with monotherapy regimens of a calcium channel antagonist or an angiotensin II receptor blocker. The two drugs in a functional combination preparation herein have different activities. Composition of amlodipine (dihydropyridine-based calcium channel blocker) and losartan (angiotensin-2 receptor blocker) can achieve improved preventive or therapeutic effects for cardiovascular disorders, such as angina pectoris, hypertension, artery vasospasm, deep vein, cardiac hypertrophy, cerebral infarct, congestive heart failure and myocardial infarction, as compared with conventional single formulations, while minimizing adverse effects of the two drugs and also lower the risk of circulatory complications. The combination drug therapy for the better management of hypertension is recommended. The main objective for combination therapy is to encourage the use of lower doses of drug to reduce the patient's blood pressure, to minimize dose dependent side effects and adverse reactions. When smaller doses of medication with different mechanism of action are combined, synergistic or additive effects on blood pressure are achieved. Amlodipine besilate is a long-acting calcium channel blocker (dihydropyridine class) used as an anti-hypertensive and in the treatment of angina. Like other calcium channel blockers, amlodipine acts by relaxing the smooth muscle in the arterial wall, decreasing total peripheral resistance and hence reducing blood pressure; in angina it increases blood flow to the heart muscle. Losartan is an Angiotensin II receptor antagonist drug used mainly to treat high blood pressure. It may also delay progression of diabetic nephropathy, and is also indicated for the reduction of renal disease progression in patients with Type 2 diabetes, hypertension and micro albuminuria ${ }^{1-3}$.

\section{MATERIALS AND METHODS}

Amlodipine besilate, Losartan potassium, Micro crystalline cellulose, sodium starch glycolate, crospovidone were received from Madras Pharmaceuticals, Chennai, India. Other materials used were purchased from local vendor and were of analytical grade.

\section{Experimental work \\ Pre formulation Studies}

Physicochemical Interaction of drug and polymer

Physicochemical Interaction of drug and excipients for amlodipine was done as per IP by the identification test carried out by the Fourier Transform Infra red spectrophotometer (FTIR) and the report was shown in Figure 1.

\section{Manufacturing process of Losartan potassium immediate release granules}

Sift the weighed quantities of Losartan Potassium, Microcrystalline cellulose plain, starch plain and Polyplasdone XL10 through Mesh 30\#. Transfer the sifted materials and Binder solution to Granulation area. Load the sifted material into the main bowl of rapid mixer and mix it for 15 minutes. Transfer the sifted materials into FBD main bowl. Dry the granules at 50 degrees Celsius. Sift the SemiDried granules through Mesh $20 \#$ and pass the retained 
granules through Multi-Mill fitted with $1.0 \mathrm{~mm}$ screen using knives forward medium speed. Transfer the semidried sifted and milled granules into FBD bowl. Dry the semidried sifted granules at 50 degrees Celsius till the required LOD is achieved. Check the LOD of the granules (Limit: Between $2.0-4.0 \% \mathrm{w} / \mathrm{w}$ at $105^{\circ} \mathrm{C}$ ). Sift the following materials Pre gelatinised Starch, and Polyplasdone XL10 through Mesh 30\#. Load the sifted dried granules along with the above sifted materials into blender and blend it for 10 minutes. Finally sift Magnesium Stearate through Mesh 60\# and mix for 5 minutes.

Manufacturing process of Amlodipine besilate layer blend Sift the weighed quantities of Amlodipine Besilate, Dicalcium Phosphate Anhydrous, Micro crystalline cellulose $\mathrm{pH} 102$, starch 1500, sodium starch glycolate, colloidal silicon dioxide and pass through Mesh 30\#. Ponceau 4R Lake was passed through Mesh 100\# and added to the above blend. Load the sifted materials such as Amlodipine Besilate, Dicalcium Phosphate Anhydrous, Micro crystalline cellulose pH 102, Starch 1500, Sodium Starch glycolate, colloidal silicon dioxide and Ponceau 4R Lake in Hexagonal blender and mix for 15 minutes. Sift Magnesium Stearate through Mesh 60\# and add to the above mixture in the blender and mix for another 5 minutes.

\section{Evaluation of Flow Property of Granules}

The prepared granules were evaluated for flow property like bulk density, tapped density, carr index, Hausner ratio, angle of repose and results were tabulated in Table 2.

\section{Compression of Bi layer Tablets}

The quantity of granules for the immediate-release layer was compressed lightly using 27 stationary double rotary compression machine (Cad mach, India) using 13/32 inch circular standard plain punches. Over this compressed layer, required quantity of the other immediate release layer was placed and compressed to obtain hardness in the range of 8 $12 \mathrm{~kg} / \mathrm{cm}^{2}$ to form a bi layer tablet of immediate release of Losartan potassium and Immediate release of Amlodipine besilate. Then the compressed bi layer tablets were evaluated.

\section{Coating of Bi layer Tablets}

\section{Film coating solution preparation}

Isopropyl alcohol was transferred into a clean stainless steel vessel. Instacoat (IC-S-10) was added to the part of isopropyl alcohol. To another part of isopropyl alcohol, quinoline yellow lake was added and was passed through the colloidal mill and mixed with the above solution. Finally methylene chloride was added to the above solution with continuous stirring. Care was taken that there were no lumps formation in the solution visually. The above solution was filtered through mesh 100\# nylon cloth. The above solution was transferred into a SS vessel of pressure vessel fitted with stirrer.

\section{Evaluation of Tablets}

All the tablets were evaluated for different parameters like hardness, thickness, friability, drug content, disintegration time, in-vitro drug Release ${ }^{4}$.

\section{Thickness}

Thickness depends on die filling, physical properties of material to be compressed. There is possibility of small variation in the thickness of individual tablet in a batch. But it should not be apparent to the unaided eye. The thickness and diameter was measured by vernier calipers. The results were shown in Table 3.

\section{Hardness}

Tablet must possess sufficient strength or hardness and can be measured by Monsanto hardness tester. Ten tablets were randomly picked from each formulation and were evaluated for hardness and can be expressed in $\mathrm{Kg} / \mathrm{cm}^{2}$. The results were shown in Table 3.

\section{Friability}

Friability can be performed in Roche friabilator, Pre weighed ten tablets were introduced in the friabilator. Then the machine was operated for 100 revolutions. Tablets were dropping from a distance of six inches with each revolution. Tablets were then dusted and reweighed. Loss of less than 1 $\%$ in weight is considered to be within the specifications and acceptable. The results were shown in Table 3.

$$
\mathrm{F}(\%) \frac{\text { Initial wt. }- \text { Final wt. }}{\text { Initial wt. }} \quad \times 100
$$

\section{Weight variation test}

Twenty tablets were selected randomly and weighed individually. The average weight was calculated and compared with the individual tablet weight to the average. Not more than two of the individual weights deviate from the average weight by more than the percentage of $5 \%$ and none deviate by more than twice the percentage. The results were shown in Table 5.

\section{Disintegration Time}

The in-vitro disintegration time was determined by using disintegration test apparatus. One tablet was placed in each of the six tubes of the apparatus and one disc was added to each tube. The time in seconds taken for complete disintegration of the tablet with no palpable mass in the apparatus was measured in seconds. The results were shown in Table 3 .

\section{Drug content: Assay: (BY HPLC)}

For Amlodipine Besilate and Losartan Potassium

\section{Procedure}

\section{Chromatographic System}

Apparatus: HPLC, PDA detector, Column: Inertsil ODS C8 $25 \times 4.9 \mathrm{~mm}$, Column temperature: Ambient, Flow rate: 1.0 $\mathrm{ml} /$ minute, Injection volume: $20 \mu \mathrm{l}$, Detector Wave length: $237 \mathrm{~nm}$, Run time : 25 minutes, Diluent: Buffer: Methanol: ACN (55:18:12), Instrument set up: isocratic.

\section{Standard Preparation}

Weigh accurately $40 \mathrm{mg}$ of Amlodipine from amlodipine besilate working standard and transfer into a $100 \mathrm{ml}$ volumetric flask, dissolve and dilute to volume with mobile phase (Solution A). $40 \mathrm{mg}$ of losartan potassium was weighed transferred into standard volumetric flask and $10 \mathrm{ml}$ of solution A was added and the volume was made up with the mobile phase.

\section{Sample Preparation}

10 tablets were randomly selected from collected samples of analysis, Powdered and transferred into $250 \mathrm{ml}$ standard flask. $170 \mathrm{ml}$ of mobile phase was added in the flask, 
dissolved and sonicated for 30 minutes and diluted to the volume with the mobile phase. $5 \mathrm{ml}$ of the above solution was transferred to $25 \mathrm{ml}$ standard flask and volume was made to $25 \mathrm{ml}$.

Procedure: Inject $20 \mu \mathrm{L}$ portion of diluents as blank, 6 replicate injections of standard preparation and one injection of each test preparation into the HPLC system, record the chromatograms and measure the peaks response.

\section{In vitro Dissolution studies}

\section{Procedure of Dissolution of bi layer tablets}

Six tablets of Amlodipine Besilate and Losartan Potassium (Bi layer tablets) were introduced in the dissolution apparatus USP Type II (paddle). The medium used was $900 \mathrm{ml}$ of 0.01 $\mathrm{M}$ sodium acetate buffer, $\mathrm{pH} 4.5$ maintained with glacial acetic acid and the dissolution mediums were maintained at the temperature of $37.5 \pm 0.5^{\circ} \mathrm{C}$, the RPM was set at 75 . The Dissolution was carried out for 30 minutes and sample withdrawn at pre determined intervals. The estimation was carried out by HPLC method. The optimized formulation was compared with the market product. The readings were shown in Table 4.

\section{Estimation of Amlodipine by HPLC Chromatographic system}

Apparatus: HPLC, PDA Detector, Column: Inertsil ODS C8, $250 \times 4.6 \mathrm{~mm}$, Wave length: $237 \mathrm{~nm}$, Injection volume: 50 $\mu 1$, Flow rate: $1.0 \mathrm{ml} / \mathrm{min}$, Column Temperature: Ambient, Diluent: Dissolution medium, Mobile phase: Buffer: Methanol: ACN (55:18:22), Retention time: 15 minutes, Instrument set up: Isocratic.

\section{Standard Preparation}

Accurately $75.3 \mathrm{mg}$ of Amlodipine besilate was taken in 100 $\mathrm{ml}$ of volumetric flask and $25 \mathrm{ml}$ of diluents were added and sonicated to dissolve and the volume was made up with diluents to $100 \mathrm{ml}$. From this $10 \mathrm{ml}$ was pipette out in to 100 $\mathrm{ml}$ volumetric flask and volume was made with a diluents. From the above solution another $10 \mathrm{ml}$ withdrawn and made up to $100 \mathrm{ml}$ and Filtered through 0.45 micron membrane filter.

\section{Sample Preparation}

The dissolution parameters were set and one tablet is placed in each basket and care was taken to exclude air bubbles from the surface of the tablets and immediately the apparatus was started, $10 \mathrm{ml}$ of the sample was withdrawn and filter through whatmann filter paper, $10 \mathrm{ml}$ of solution was replaced in to dissolution medium, the same procedure was repeated at other time intervals.

\section{Procedure}

50 micro litre of filtered portion of the standard and sample solution was injected in to HPLC system. The chromatogram was recorded and responses were measured for major peaks.

\section{Estimation of Losartan by HPLC} Chromatographic system

Apparatus: HPLC, PDA Detector, Column: Inertsil ODS C8, $250 \times 4.6 \mathrm{~mm}$, Wave length: $237 \mathrm{~nm}$, Injection volume: 50 $\mu 1$, Flow rate: $1.0 \mathrm{ml} / \mathrm{min}$, Column Temperature: Ambient, Diluent: Acetonitrile and Dissolution medium, Mobile phase: Buffer: Methanol: ACN (55:18:22), Retention time: 15 minutes, Instrument set up: Isocratic.
Standard Preparation

Accurately weighed $56.9 \mathrm{mg}$ of Losartan Potassium was taken in $100 \mathrm{ml}$ volumetric flask and $50 \mathrm{ml}$ of diluents and volume was made up by the diluents to $100 \mathrm{ml}$. From this 10 $\mathrm{ml}$ was pipette out in to $100 \mathrm{ml}$ volumetric flask and volume was made up with dissolution medium.

\section{Sample Preparation}

The dissolution parameters were set and one tablet was placed in to each basket care was taken to exclude air bubbles from the surface of the tablets and immediately the apparatus was started, $10 \mathrm{ml}$ of the sample was withdrawn and filter through whatmann filter paper, $10 \mathrm{ml}$ of solution was replaced in to dissolution medium, the same procedure was repeated at other time intervals.

\section{Procedure}

50 micro litres of filtered portion of the standard and sample solution was injected in to HPLC system. The chromatogram was recorded and the responses were measured for the major peaks.

\section{Stability Studies}

The stability studies were carried out according to ICH to assess the drug formulation stability. Optimized F8 formulation was sealed in aluminium packaging laminated with polyethylene. Samples were kept at $40^{\circ} \mathrm{C}$ and $75 \% \mathrm{RH}$ for 1, 2, 3, 6 months. At the end of the study period, the formulation was observed for change in physical appearance, colour and drug content and drug release characteristics ${ }^{5}$.

\section{RESULTS AND DISCUSSION}

Drug-expipient interactions were studied using Infrared spectroscopy. The results show that there was no interaction between the drug and excipients.

\section{Pre Compression Studies}

The angle of repose for the formulated blend was carried out; it concludes the entire formulations blend for amlodipine besilate was found to be in the range $26.30^{\circ}$ to $29.80^{\circ}$ and for losartan potassium it was found to be in the range of $26.20^{\circ}$ to $32.50^{\circ}$. Hence the entire formulations blend was found to be good, passable flow property. Compressibility index was carried out; it was found between $14.32 \%$ to $21.20 \%$ for Amlodipine besilate blend and $18.19 \%$ to $20.89 \%$ for losartan potassium blend indicating the powder blend has the required flow property for compression. Hausner's ratio was calculated for the blend, it found between 1.16 -1.27 for amlodipine besilate and $1.09-1.26$ for losartan potassium indicating Powder blend has the required flow property for compression. The results were shown in Table 2.

\section{Evaluation of Bi layer tablets}

The hardness, friability, thickness, percentage weight variation, disintegration time, drug content was evaluated for prepared tablets the results were shown in Table 3. The measured hardness of tablets of each batch ranged between $6.4 \pm 0.57$ to $8.9 \pm 0.69 \mathrm{~kg} / \mathrm{cm}^{2}$. This ensures good handling characteristics of all batches. The \% friability was less than 1 $\%$ in all the formulations ensuring that the tablets were mechanically stable. The percentage weight variations for all formulations were calculated. 
Rama et al. Int. Res. J. Pharm. 2013, 4 (9)

\begin{tabular}{|c|c|c|c|c|c|c|c|c|}
\hline \multicolumn{9}{|c|}{ Table 1: Formulation Trials of Bi layer tablets } \\
\hline Ingredients & $\begin{array}{c}\text { F-1 } \\
(\mathrm{Mg} / \mathrm{tab})\end{array}$ & $\begin{array}{c}\text { F-2 } \\
(\mathrm{Mg} / \mathrm{tab})\end{array}$ & $\begin{array}{c}\mathrm{F}-3 \\
(\mathrm{Mg} / \mathrm{tab})\end{array}$ & $\begin{array}{c}\text { F-4 } \\
(\mathrm{Mg} / \mathrm{tab})\end{array}$ & $\begin{array}{c}\text { F-5 } \\
(\mathrm{Mg} / \mathrm{tab})\end{array}$ & $\begin{array}{c}\text { F-6 } \\
(\mathrm{Mg} / \mathrm{tab})\end{array}$ & $\begin{array}{c}\text { F-7 } \\
(\mathrm{Mg} / \text { tab) }\end{array}$ & $\begin{array}{c}\text { F-8 } \\
(\mathrm{Mg} / \mathrm{tab})\end{array}$ \\
\hline \multicolumn{9}{|c|}{ Losartan Layer } \\
\hline Losartan Potassium & 50.00 & 50.00 & 50.00 & 50.00 & 50.00 & 50.00 & 50.00 & 50.00 \\
\hline MCC Plain & 175.50 & 165.50 & 148.50 & 139.00 & 127.50 & 110.50 & 104.00 & 95.00 \\
\hline Starch Plain & - & 10.00 & 10.00 & 15.00 & 15.00 & 25.00 & 25.00 & 30.00 \\
\hline Crospovidone XL 10 & - & - & 5.00 & 5.00 & 7.00 & 7.00 & 9.00 & 11.00 \\
\hline P.Water(For Granulation) & q.s & q.s & q.s & q.s & q.s & q.s & q.s & q.s \\
\hline \multicolumn{9}{|c|}{ Lubrication } \\
\hline Pregelatinised starch & - & - & 7.50 & 7.50 & 15.00 & 20.00 & 22.50 & 22.50 \\
\hline Crospovidone XL 10 & - & - & 4.50 & 9.00 & 11.00 & 13.00 & 15.00 & 17.00 \\
\hline Magnesium Stearate & 4.50 & 4.50 & 4.50 & 4.50 & 4.50 & 4.50 & 4.50 & 4.50 \\
\hline \multicolumn{9}{|c|}{ Amlodipine Layer } \\
\hline Amlodipine Besylate & 7.00 & 7.00 & 7.00 & 7.00 & 7.00 & 7.00 & 7.00 & 7.00 \\
\hline DCP & 45.00 & 43.00 & 43.00 & 42.00 & 42.00 & 40.00 & 40.00 & 40.00 \\
\hline MCC pH102 & 65.0 & 65.00 & 62.00 & 62.00 & 57.00 & 58.00 & 58.00 & 58.00 \\
\hline Pre gelatinised Starch & - & 2.00 & 4.00 & 4.00 & 8.00 & 8.00 & 8.00 & 8.00 \\
\hline SSG & - & - & 1.00 & 2.00 & 3.00 & 4.00 & 4.00 & 4.00 \\
\hline Aerosil & 1.00 & 1.00 & 1.00 & 1.00 & 1.00 & 1.00 & 1.00 & 1.00 \\
\hline Ponceau 4R Lake & 1.00 & 1.00 & 1.00 & 1.00 & 1.00 & 1.00 & 1.00 & 1.00 \\
\hline Magnesium Stearate & 1.00 & 1.00 & 1.00 & 1.00 & 1.00 & 1.00 & 1.00 & 1.00 \\
\hline Total weight & 350 & 350 & 350 & 350 & 350 & 350 & 350 & 350 \\
\hline
\end{tabular}

Table 2: Pre compression parameters for Amlodipine and losartan potassium layer blend

\begin{tabular}{|c|c|c|c|c|c|}
\hline Formulation & Bulk Density (g/ml) & Tapped Density (g/ml) & Hausner's Ratio & Carr's Index (\%) & Angle of Repose ( $\theta$ ) \\
\hline $\mathrm{A} 1$ & $0.634 \pm 0.002$ & $0.740 \pm 0.001$ & $1.16 \pm 0.01$ & $14.32 \pm 0.65$ & $26.3^{\circ} \pm 0.98$ \\
\hline $\mathrm{A} 2$ & $0.623 \pm 0.001$ & $0.754 \pm 0.003$ & $1.21 \pm 0.01$ & $17.37 \pm 0.87$ & $29.8^{\circ} \pm 1.17$ \\
\hline A3 & $0.578 \pm 0.002$ & $0.722 \pm 0.004$ & $1.25 \pm 0.03$ & $19.94 \pm 1.11$ & $28.8^{\circ} \pm 0.75$ \\
\hline A4 & $0.595 \pm 0.004$ & $0.758 \pm 0.002$ & $1.27 \pm 0.01$ & $21.20 \pm 0.87$ & $28.6^{\circ} \pm 0.88$ \\
\hline A5 & $0.589 \pm 0.001$ & $0.737 \pm 0.002$ & $1.25 \pm 0.02$ & $20.08 \pm 0.45$ & $28.4^{\circ} \pm 1.24$ \\
\hline A6 & $0.613 \pm 0.003$ & $0.766 \pm 0.003$ & $1.24 \pm 0.02$ & $19.73 \pm 0.72$ & $29.4^{\circ} \pm 1.32$ \\
\hline L1 & $0.488 \pm 0.002$ & $0.605 \pm 0.002$ & $1.17 \pm 0.01$ & $19.39 \pm 0.89$ & $30.4^{\circ} \pm 1.40$ \\
\hline L2 & $0.479 \pm 0.003$ & $0.604 \pm 0.006$ & $1.25 \pm 0.01$ & $20.60 \pm 1.12$ & $31.7^{\circ} \pm 1.23$ \\
\hline L3 & $0.491 \pm 0.001$ & $0.617 \pm 0.001$ & $1.26 \pm 0.03$ & $20.89 \pm 1.45$ & $32.5^{\circ} \pm 0.95$ \\
\hline L4 & $0.487 \pm 0.002$ & $0.612 \pm 0.002$ & $1.25 \pm 0.01$ & $20.41 \pm 1.23$ & $31.8^{\circ} \pm 0.89$ \\
\hline L5 & $0.490 \pm 0.007$ & $0.599 \pm 0.002$ & $1.09 \pm 0.02$ & $18.19 \pm 1.16$ & $26.2^{\circ} \pm 1.15$ \\
\hline L6 & $0.479 \pm 0.008$ & $0.605 \pm 0.001$ & $1.26 \pm 0.01$ & $20.82 \pm 1.31$ & $29.9^{\circ} \pm 1.63$ \\
\hline L7 & $0.486 \pm 0.009$ & $0.609 \pm 0.003$ & $1.25 \pm 0.02$ & $20.32 \pm 0.93$ & $29.4^{\circ} \pm 1.34$ \\
\hline L8 & $0.477 \pm 0.005$ & $0.600 \pm 0.004$ & $1.25 \pm 0.02$ & $20.51 \pm 0.96$ & $30.3^{\circ} \pm 0.90$ \\
\hline
\end{tabular}

Table 3: Post compression parameters for bi layer tablets

\begin{tabular}{|c|c|c|c|c|c|c|}
\hline Batch & Thickness (mm) & Hardness $\left(\mathrm{kg} / \mathrm{cm}^{2}\right)$ & Friability \% & Disintegration Time (Minutes) & Assay \% & Weight Variation Test \\
\hline \multirow[t]{2}{*}{ F-1 } & \multirow[t]{2}{*}{$4.09 \pm 0.011$} & \multirow[t]{2}{*}{$6.4 \pm 0.57$} & \multirow[t]{2}{*}{0.22} & \multirow[t]{2}{*}{$11 \mathrm{~m} 53 \mathrm{~s}$} & (A)-92.32 & \multirow[t]{2}{*}{$362 \pm 1.75$} \\
\hline & & & & & (L)-97.34 & \\
\hline \multirow[t]{2}{*}{$\mathrm{F}-2$} & \multirow[t]{2}{*}{$4.21 \pm 0.015$} & \multirow[t]{2}{*}{$7.3 \pm 0.73$} & \multirow[t]{2}{*}{0.19} & \multirow[t]{2}{*}{$9 \mathrm{~m} \mathrm{14s}$} & (A)-91.66 & \multirow[t]{2}{*}{$371 \pm 2.6$} \\
\hline & & & & & (L)-98.15 & \\
\hline \multirow[t]{2}{*}{ F-3 } & \multirow[t]{2}{*}{$4.32 \pm 0.014$} & \multirow[t]{2}{*}{$7.8 \pm 0.34$} & \multirow[t]{2}{*}{0.13} & \multirow[t]{2}{*}{$7 \mathrm{~m} \mathrm{40s}$} & (A)-90.78 & \multirow[t]{2}{*}{$364 \pm 2.23$} \\
\hline & & & & & (L)-97.56 & \\
\hline \multirow[t]{2}{*}{ F-4 } & \multirow[t]{2}{*}{$4.28 \pm 0.012$} & \multirow[t]{2}{*}{$8.9 \pm 0.69$} & \multirow[t]{2}{*}{0.09} & \multirow[t]{2}{*}{$7 \mathrm{~m} \mathrm{47s}$} & (A)-94.98 & \multirow[t]{2}{*}{$369 \pm 1.98$} \\
\hline & & & & & (L)-96.87 & \\
\hline \multirow[t]{2}{*}{ F-5 } & \multirow[t]{2}{*}{$4.24 \pm 0.011$} & \multirow[t]{2}{*}{$8.5 \pm 0.76$} & \multirow[t]{2}{*}{0.15} & \multirow[t]{2}{*}{$6 \mathrm{~m} \mathrm{18s}$} & (A)-93.71 & \multirow[t]{2}{*}{$358 \pm 1.81$} \\
\hline & & & & & (L)-97.87 & \\
\hline \multirow[t]{2}{*}{ F-6 } & \multirow[t]{2}{*}{$4.35 \pm 0.010$} & \multirow[t]{2}{*}{$6.4 \pm 0.43$} & \multirow[t]{2}{*}{0.22} & \multirow[t]{2}{*}{$6 \mathrm{~m} \mathrm{41s}$} & (A)-92.45 & \multirow[t]{2}{*}{$365 \pm 2.55$} \\
\hline & & & & & (L)-94.79 & \\
\hline \multirow[t]{2}{*}{ F-7 } & $4.26 \pm 0.011$ & $7.9 \pm 0.67$ & 0.18 & $6 \mathrm{~m} 25 \mathrm{~s}$ & (A)-94.06 & $370 \pm 2.85$ \\
\hline & & & & & (L) -95.50 & \\
\hline F-8 & $4.19 \pm 0.013$ & $8.8 \pm 0.82$ & 0.17 & $5 \mathrm{~m} \mathrm{30s}$ & (A)-94.70 & $363 \pm 2.05$ \\
\hline & & & & & (L)-96.87 & \\
\hline
\end{tabular}

Table 4: In Vitro Dissolution Study of Amlodipine besilate and Losartan Potassium bilayer tablets

\begin{tabular}{|c|c|c|c|c|c|c|c|c|c|}
\hline \multirow{2}{*}{$\begin{array}{c}\text { Time } \\
\text { (minutes) }\end{array}$} & \multirow{2}{*}{$\begin{array}{c}\text { Formulation } \\
\text { Layer }\end{array}$} & \multicolumn{8}{|c|}{ Percentage Drug release } \\
\hline & & F1 & F2 & F3 & F4 & F5 & F6 & F7 & F8 \\
\hline \multirow[t]{2}{*}{5} & Amlodipine & $24.63 \pm 0.08$ & $39.50 \pm 0.14$ & $50.60 \pm 0.16$ & $55.87 \pm 0.09$ & $72.13 \pm 0.10$ & $71.87 \pm 0.08$ & $70.53 \pm 0.05$ & $73.12 \pm 0.06$ \\
\hline & Losartan & $21.12 \pm 0.21$ & $26.36 \pm 0.11$ & $38.05 \pm 0.10$ & $45.67 \pm 0.16$ & $61.72 \pm 0.08$ & $69.14 \pm 0.12$ & $74.12 \pm 0.11$ & $77.67 \pm 0.08$ \\
\hline \multirow[t]{2}{*}{10} & Amlodipine & $42.40 \pm 0.13$ & $53.76 \pm 0.23$ & $57.42 \pm 0.21$ & $64.12 \pm 0.14$ & $78.97 \pm 0.12$ & $77.46 \pm 0.10$ & $78.12 \pm 0.09$ & $79.54 \pm 0.14$ \\
\hline & Losartan & $36.54 \pm 0.43$ & $39.93 \pm 0.19$ & $52.38 \pm 0.11$ & $61.95 \pm 0.11$ & $72.17 \pm 0.15$ & $76.87 \pm 0.18$ & $78.70 \pm 0.15$ & $83.82 \pm 0.12$ \\
\hline \multirow[t]{2}{*}{15} & Amlodipine & $52.13 \pm 0.19$ & $59.98 \pm 0.12$ & $64.54 \pm 0.15$ & $71.26 \pm 0.10$ & $82.13 \pm 0.11$ & $82.76 \pm 0.19$ & $81.23 \pm 0.18$ & $82.17 \pm 0.11$ \\
\hline & Losartan & $49.60 \pm 0.24$ & $58.12 \pm 0.15$ & $66.85 \pm 0.19$ & $73.92 \pm 0.25$ & $76.32 \pm 0.22$ & $81.53 \pm 0.17$ & $84.21 \pm 0.14$ & $85.05 \pm 0.15$ \\
\hline \multirow[t]{2}{*}{20} & Amlodipine & $61.36 \pm 0.24$ & $67.78 \pm 0.24$ & $68.91 \pm 0.23$ & $77.10 \pm 0.56$ & $83.42 \pm 0.29$ & $83.15 \pm 0.49$ & $82.87 \pm 0.31$ & $83.21 \pm 0.55$ \\
\hline & Losartan & $56.65 \pm 0.36$ & $64.73 \pm 0.33$ & $73.50 \pm 0.54$ & $77.65 \pm 0.41$ & $81.56 \pm 0.12$ & $84.21 \pm 0.34$ & $86.78 \pm 0.44$ & $88.12 \pm 0.48$ \\
\hline \multirow[t]{2}{*}{25} & Amlodipine & $68.67 \pm 0.16$ & $73.31 \pm 0.28$ & $74.23 \pm 0.87$ & $80.90 \pm 0.67$ & $83.91 \pm 0.45$ & $84.12 \pm 0.70$ & $84.25 \pm 0.19$ & $83.64 \pm 0.37$ \\
\hline & Losartan & $62.81 \pm 0.87$ & $69.88 \pm 0.56$ & $74.81 \pm 0.75$ & $80.03 \pm 0.78$ & $83.94 \pm 0.26$ & $86.92 \pm 0.45$ & $88.79 \pm 0.54$ & $89.85 \pm 0.71$ \\
\hline \multirow[t]{2}{*}{30} & Amlodipine & $73.62 \pm 0.21$ & $76.15 \pm 0.75$ & $79.71 \pm 0.39$ & $82.23 \pm 0.39$ & $84.23 \pm 0.47$ & $84.88 \pm 0.34$ & $84.32 \pm 0.29$ & $84.02 \pm 0.68$ \\
\hline & Losartan & $68.40 \pm 0.67$ & $72.25 \pm 0.56$ & $77.59 \pm 0.81$ & $80.29 \pm 0.61$ & $85.56 \pm 0.19$ & $87.15 \pm 0.38$ & $89.09 \pm 0.28$ & $90.08 \pm 0.42$ \\
\hline
\end{tabular}


Rama et al. Int. Res. J. Pharm. 2013, 4 (9)

\begin{tabular}{|c|c|c|c|c|c|c|}
\hline \multirow[t]{3}{*}{ S. No } & \multirow[t]{3}{*}{ Parameters } & \multicolumn{5}{|c|}{ Conditions } \\
\hline & & Initial & $40^{\circ} \mathrm{C}$ and $75 \% \mathrm{RH}$ & $40^{\circ} \mathrm{C}$ and $75 \% \mathrm{RH}$ & $40^{\circ} \mathrm{C}$ and $75 \% \mathrm{RH}$ & $40^{\circ} \mathrm{C}$ and $75 \% \mathrm{RH}$ \\
\hline & & 0 Day & 1 month & 2 month & 3 month & 6 month \\
\hline 1 & Average weight & $363 \pm 5 \mathrm{mg}$ & $363 \pm 5 \mathrm{mg}$ & $363 \pm 5 \mathrm{mg}$ & $363 \pm 5 \mathrm{mg}$ & $363 \pm 5 \mathrm{mg}$ \\
\hline 2 & Thickness (mm) & $4.31 \pm 0.014$ & $4.31 \pm 0.014$ & $4.31 \pm 0.014$ & $4.31 \pm 0.014$ & $4.31 \pm 0.014$ \\
\hline 3 & Disintegration time & 6 minutes $45 \mathrm{sec}$ & 7 minutes $17 \mathrm{sec}$ & 7 minutes $23 \mathrm{sec}$ & 7 minutes $20 \mathrm{sec}$ & 7 minutes $55 \mathrm{sec}$ \\
\hline \multirow[t]{2}{*}{4} & \multirow[t]{2}{*}{ Assay $(\%)$} & A-94.70 & A-94.66 & A-94.49 & A-94.45 & A-94.21 \\
\hline & & L-96.87 & L-96.81 & L-96.74 & L-96.72 & L-96.50 \\
\hline \multirow[t]{2}{*}{5} & \multirow{2}{*}{$\begin{array}{c}\text { Dissolution } \\
\text { (30 minutes) }\end{array}$} & A-84.02 & A-83.98 & A-83.89 & A-83.86 & A-83.53 \\
\hline & & L-90.08 & L-89.91 & L-89.88 & L-89.85 & L-89.71 \\
\hline
\end{tabular}

\section{Physicochemical Interaction of Drug and Excipients}

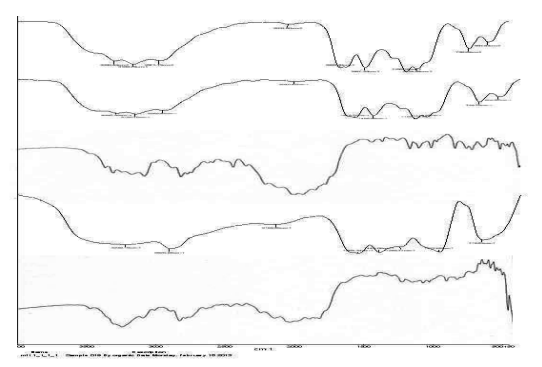

Figure 1: IR Spectra of Pure drugs (amlodipine and losartan), tablet (amlodipine layer and losartan layer) and coated tablet

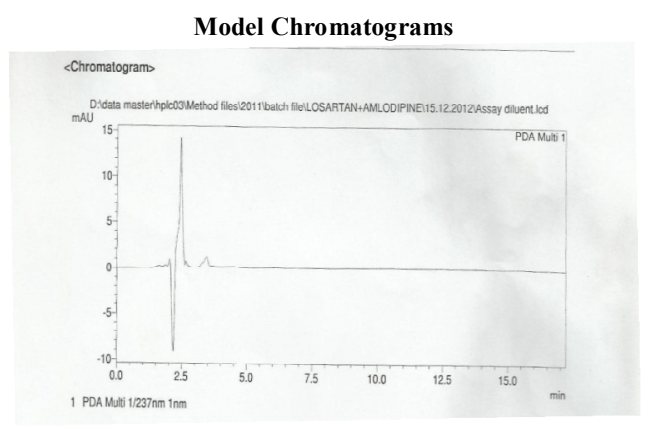

Figure 2: HPLC chromotograph of diluents, sample and standard

Figure 2(a): Assay Diluent sample

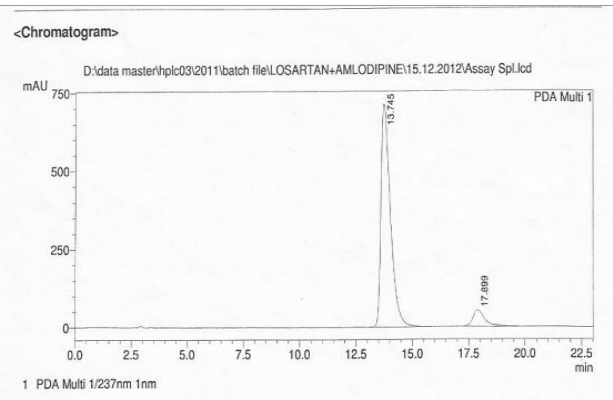

Figure 2(b): Assay Sample

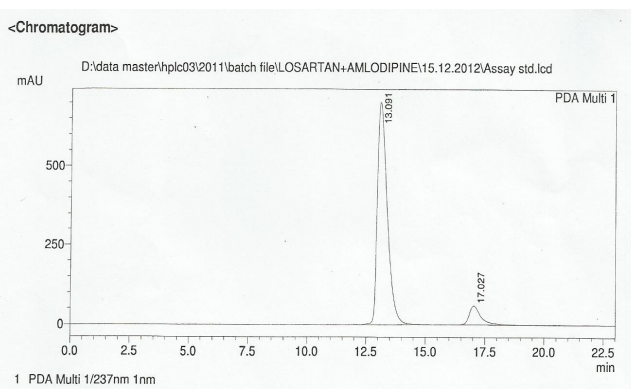

Figure 2(c): Assay Standard 


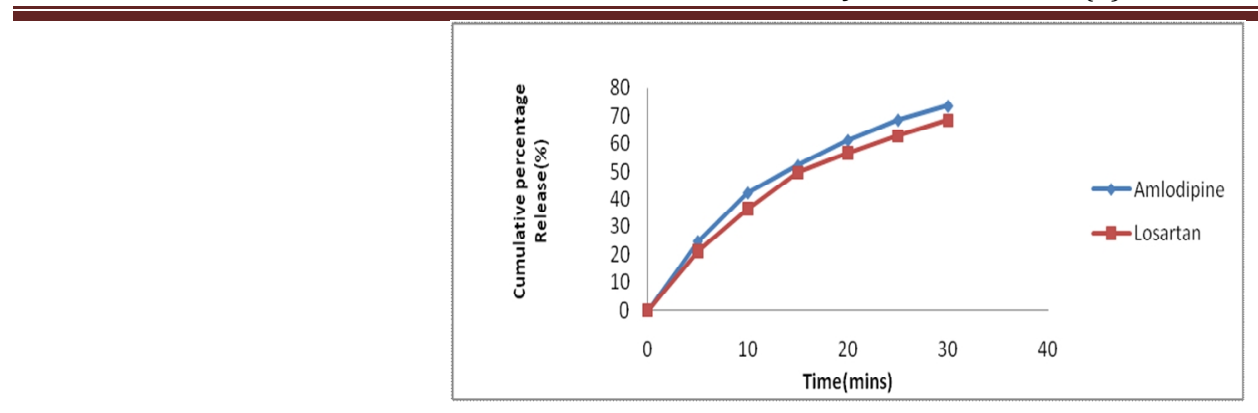

Figure 3: In vitro Dissolution Profile of Different Formulations Figure 3 (a): In vitro Dissolution Profile for Formulation F1

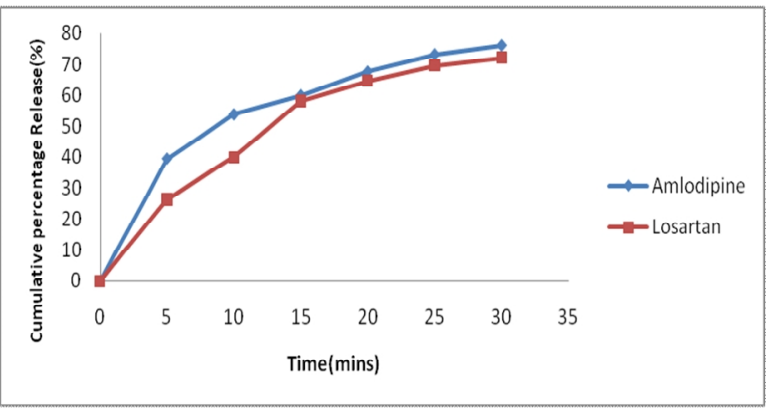

Figure 3(b): In vitro Dissolution Profile for Formulation F2

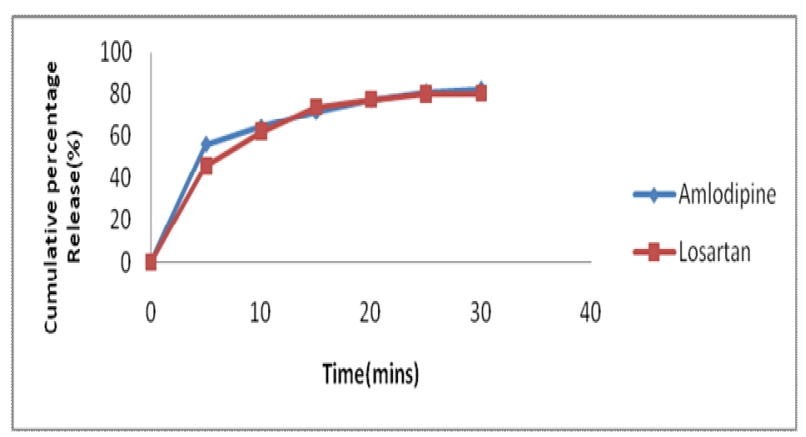

Figure 3 (d): In vitro Dissolution Profile for Formulation F4

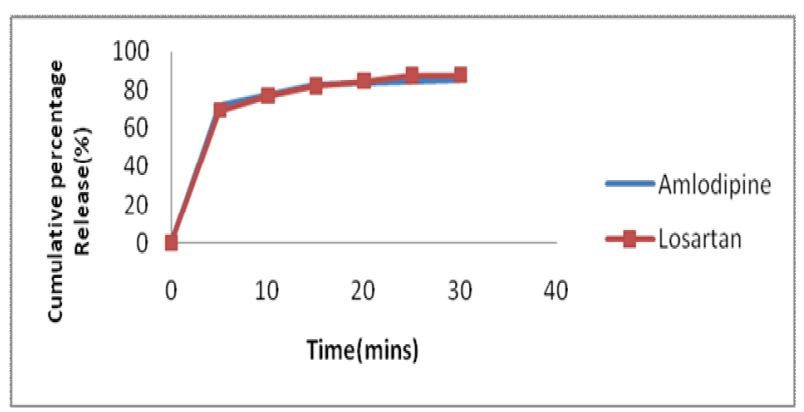

Figure 3 (f): In vitro Dissolution Profile for Formulation F6

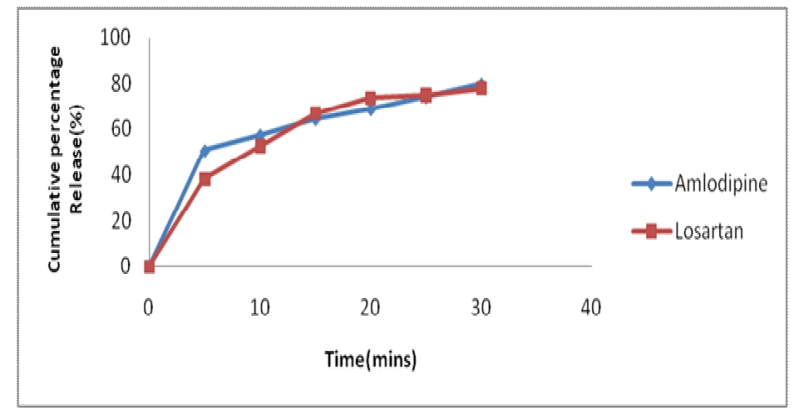

Figure 3 (c): In vitro Dissolution Profile for Formulation F3

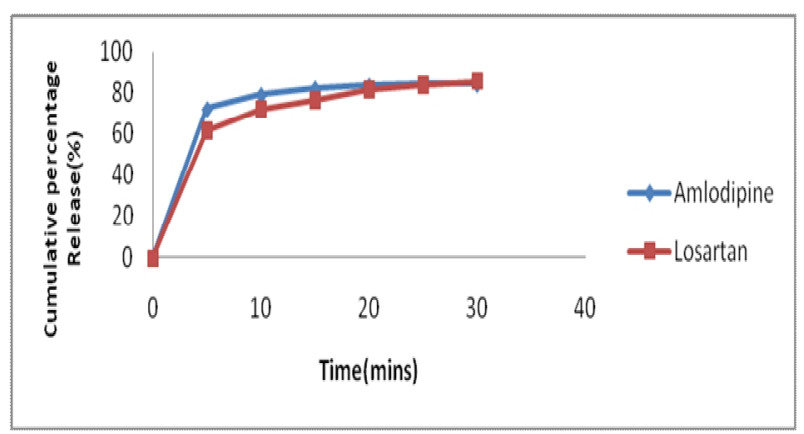

Figure 3 (e): In vitro Dissolution Profile for Formulation F5

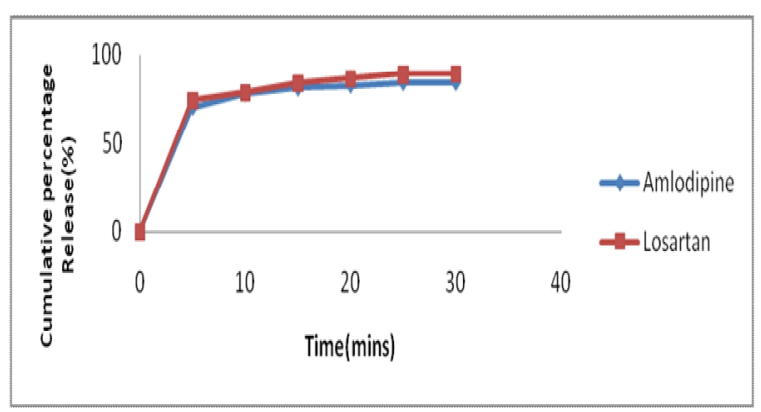

Figure 3 (g): In vitro Dissolution Profile For Formulation F7 


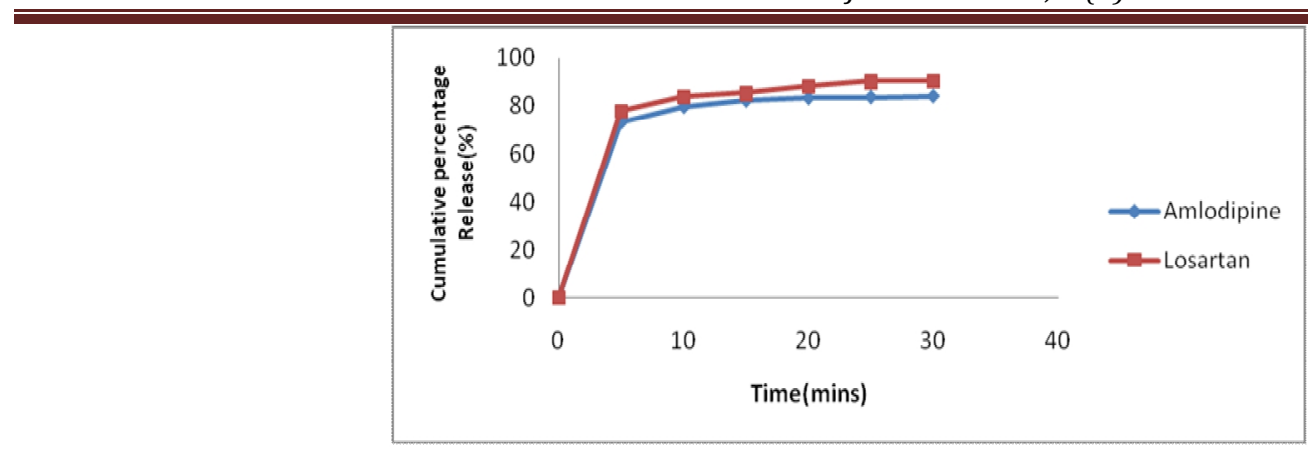

Figure 3 (h): In vitro Dissolution Profile For Formulation F8

All the formulated (F1 to F8) tablets passed weight variation test as the Percentage weight variation was within the pharmacopoeia limits of $7.5 \%$ of the weight. The weights of all the tablets were found to be uniform with low standard deviation values. The measured thickness of tablets of each batch ranged between $4.09 \pm 0.011$ to $4.35 \pm$ $0.010 \mathrm{~mm}$ for tablets. The disintegration time of all the batches were found between 12 minutes to 5 minutes. The percentage of drug content for F1 to F8 was found to $90.78 \%$ to $94.98 \%$ of Amlodipine besilate and $94.79 \%$ to $98.15 \%$ of Losartan Potassium and it complies with official specifications.

In vitro dissolution for all the formulations was carried out for 30 minutes. The results were shown in Table 4 . The maximum drug release was found for the optimized formulation $\mathrm{F} 8$ containing $5 \% \mathrm{w} / \mathrm{w}$ crospovidone for Losartan Potassium layer and 4 \% Sodium Starch Glycolate for Amlodipine layer shows least disintegration time and better dissolution properties compared to the other batches (F1- F7). The reason might be at the optimum concentration crospovidone rapidly exhibits high capillary action and pronounced hydration capacity and at optimum concentration of sodium starch glycolate disintegration occurs by rapid uptake of water followed by rapid and enormous swelling and hence F8 was chosen as the optimized formulation for the further stability studies.

\section{Stability Study}

According to $\mathrm{ICH}$ guidelines, 6 months accelerated stability study at $40 \pm 2^{\circ} \mathrm{c}$ and $75 \% \mathrm{RH}$ optimized formulation (F8) showed negligible change over time for parameters like appearance, drug content, dissolution, etc. No significant difference in the drug content between initial and formulations stored at $40 \pm 2^{\circ}$ and $75 \pm 5 \% \mathrm{RH}$ for 6 months.

\section{CONCLUSION}

When the combined formulation of amlodipine and losartan is prepared by simply mixing the two drugs, gelation of losartan disadvantageously occurs. Losartan readily dissolves in purified water or is very well released at a relatively high $\mathrm{pH}$ (e.g., $\mathrm{pH}$ 6.8), but it is very slowly released at a low $\mathrm{pH}$ (e.g., pH 2.0 or $\mathrm{pH}$ 1.2) because of its gelation ${ }^{6}$. In case of Cozaar (trade mark), a commercially available losartan preparation, the dissolution rate of losartan is below $30 \%$ thereof in 30 minutes at a pH range of 1.2 to 2.0 . In the combined formulation of amlodipine and losartan, amlodipine may be locked in the inside of the formulation due to the gelation of losartan. Further, the combined formulation prepared by simply mixing amlodipine and losartan has very poor storage stability mainly due to an undesired chemical reaction among amlodipine, losartan and excipients. In order to overcome the above-mentioned problems such as losartan gelation and stability lowering, the combined formulation of amlodipine and losartan must be prepared by physically separating amlodipine from losartan. The present research was carried out to develop an Immediate Release Bilayer tablet of Amlodipine Besilate and Losartan Potassium. Combination of Amlodipine Besilate and Losartan Potassium are indicated for the successful treatment and relief of hypertension. Prepared bi layer tablets were film coated in a conventional coating pan. Formulation characteristics such as content uniformity, hardness, friability were found to be satisfactory. In vitro dissolution studies of bi layer tablets were conducted for 30 minutes. Samples were analyzed by HPLC. The formulation (F-8) showed acceptable pharmaco technical properties and complied with the internal specification for weight variation, thickness, hardness, friability, drug content and in vitro drug release. Reproducibility was checked by intra batch variability study and found no pronounced variation was observed. Accelerated stability profiles of bi layer tablets were found to be satisfactory. No sign of degradation was observed in HPLC analysis. Hence, it is finally concluded that, the $\mathrm{Bi}$ layer tablet technology can be successfully applied for Immediate-release of Amlodipine Besilate and Losartan Potassium.

\section{REFERENCES}

1. Lachman L, Lieberman HA and Kanig JL. The Theory and Practice of Industrial Pharmacy, $3^{\text {rd }}$ ed. Bombay: Varghese Publishing House; 1987. p. 171-198, 293-339, 430-456.

2. YW Chien, YW Marcel. Novel Drug Delivery Systems. Published by: Marcel Dekker, $2^{\text {nd }}$ ed. New York; 2009, 199. p. 1-42.

3. Joel M Neutel. Low dose anti hypertensive combination therapy: its rationale and role in cardiovascular risk management. Am J Hypertens 1999; 12(8): 73-79. http://dx.doi.org/10.1016/S0895-7061(99)00112-0

4. Indian Pharmacopoeia. Government of India, Ministry of health and family welfare, Published by the controller of publications, Delhi; 2007. Volume I and II.

5. Bhardwaj Vineet, BansalMayank, Sharma PK. Formulation and Evaluation of fast Dissolving Tablets of Amlodipine Besilate Using Different Super Disintegrants and Camphor as Sublimating Agent. American-Eurasian J Scien Res 2010; 5(4): 264-269.

6. Singh Abhishek Kumar. Formulation and development of two incompatible anti-hypertensive drugs (losartan potassium and amlodipine besylate) in a single dose. Rajiv Gandhi University of Health Sciences, Bangalore, Karnataka.

\section{Cite this article as:}

Rama, Mitesh. R. Bhoot. Formulation and evaluation of bilayer tablets of two incompatible drugs Amlodipine besilate and Losartan potassium. Int. Res. J. Pharm. 2013; 4(9):136-142 http://dx.doi.org/10.7897/22308407.04929 